\title{
Effect of Light and $p$-Coumaric Acid on the Growth and Expression of Genes Related to Oxidative Stress in Brettanomyces bruxellensis LAMAP2480
}

\section{OPEN ACCESS}

Edited by:

Lucia M. Mendoza,

Consejo Nacional de Investigaciones

Cientificas y Técnicas (CONICET),

Argentina

Reviewed by:

Lucía González-Arenzana, Institute of Vine and Wine Sciences

(ICW), Spain

Miguel Fernández De Ullivarri,

University College Cork, Ireland

*Correspondence:

María Angélica Ganga angelica.ganga@usach.cl

Liliana Godoy

liliana.godoy@uc.cl

Specialty section:

This article was submitted to

Food Microbiology,

a section of the journal

Frontiers in Microbiology

Received: 26 July 2021 Accepted: 01 November 2021 Published: 25 November 2021

Citation:

Catrileo D, Moreira S, Ganga MA and Godoy $L$ (2021) Effect of Light and $p$-Coumaric Acid on the Growth and

Expression of Genes Related to

Oxidative Stress in Brettanomyces bruxellensis LAMAP2480.

Front. Microbiol. 12:747868. doi: 10.3389/fmich.2021.747868

\author{
Daniela Catrileo ${ }^{1}$, Sandra Moreira ${ }^{2}$, María Angélica Ganga ${ }^{2 *}$ and Liliana Godoy ${ }^{1 *}$
}

'Departamento de Fruticultura y Enología, Facultad de Agronomía e Ingeniería Forestal, Pontificia Universidad Católica de Chile, Santiago, Chile, ${ }^{2}$ Departamento de Ciencia y Tecnología de los Alimentos, Facultad Tecnológica, Universidad de Santiago de Chile, Santiago, Chile

Brettanomyces bruxellensis is considered the most significant contaminant yeast in the wine industry since it causes a deterioration in the organoleptic properties of the wine and significant economic losses. This deterioration is due to the production of volatile phenols from hydroxycinnamic acids. These compounds possess antimicrobial properties; however, $B$. bruxellensis can resist this effect because it metabolizes them into less toxic ones. Recent studies have reported that $B$. bruxellensis grows under different stress conditions, including $p$-coumaric acid $(p C A)$ but effective methods for its control have not been found yet. Since that in other yeasts, such as Saccharomyces cerevisiae, it has been described that light affects its growth, and we evaluated whether the light would have a similar effect on $B$. bruxellensis. The results show that at light intensities of 2,500 and 4,000 lux in the absence of pCA, B. bruxellensis LAMAP2480 does not grow in the culture medium; however, when the medium contains this acid, the yeast adapts to both factors of stress managing to grow. The expression of genes related to oxidative stress in B. bruxellensis LAMAP2480, such as SOD1, GCN4, and ESBP6, showed a higher relative expression when the yeast was exposed to 2,500 lux compared to 4,000 lux, agreeing with the growth curves. This suggests that a higher expression of the genes studied would be related to stress-protective effects by pCA.

Keywords: B. bruxellensis, light intensity, oxidative stress, ROS, p-coumaric acid

\section{INTRODUCTION}

Brettanomyces bruxellensis has been described as the main contaminating yeast during the winemaking process due to its ability to metabolize hydroxycinnamic acids (HCAs; $p$-coumaric acid ( $p$ CA), ferulic acid, and caffeic acid) in less toxic compounds, such as volatile phenols (Chatonnet et al., 1995; Fleet, 2003; Suárez et al., 2007; Wedral et al., 2010). This is important because HCAs have antimicrobial activity which would be metabolized by this yeast. These give off-favors to the wine, damaging its organoleptic properties (Loureiro, 2003; Suárez et al., 
2007) and causing rejection by the consumer along with significant economic losses for the industry (Loureiro, 2003; Suárez et al., 2007; Oelofse et al., 2008; Wedral et al., 2010). Godoy et al. (2016) reported a comparative analysis of the transcriptome and genome profile of the strain B. bruxellensis LAMAP2480 grown in the presence of $p C A$, and an early resistance mechanism to this acid was observed, causing generalized stress in the cell, and therefore inducing the expression of genes that encode proton pumps and mechanisms related to the release of toxic compounds.

On the other hand, the presence of this acid activates the expression of different genes related to this response, such as SOD1, ESBP6, GCN4, and HSP12 (Godoy et al., 2016). Similar results have been described for Saccharomyces cerevisiae, where the presence of $p \mathrm{CA}$ also causes an increase in reactive oxygen species (ROS) and consequently an increase in the expression of genes related to oxidative stress (Piper, 1999; de Nobel et al., 2001; Mascarenhas et al., 2008; Welker et al., 2010; Sugiyama et al., 2016). SOD1 encodes a cytosolic superoxide dismutase, which is responsible for eliminating radicals produced by the cell and toxic to it (Steinman, 1980; Jamieson, 1998). Furthermore, it has been shown that this superoxide dismutase would be part of a resistance mechanism in the presence of sorbic acid (Piper, 1999; de Nobel et al., 2001). Another gene described is ESBP6, which codes for a protein similar to a monocarboxylate permease that promotes the exit of weak acids from the cell, allowing the regulation of intracellular $\mathrm{pH}$ and reducing stress levels (Sugiyama et al., 2016; Pereira et al., 2020). Likewise, it has been identified that GCN4 gene, which codes for a basic leucine zipper domain (b-ZIP) transcription factor and is related to a protection mechanism, inhibits the growth of mutants lacking this gene, and shows overexpression in the presence of hydrogen peroxide $\left(\mathrm{H}_{2} \mathrm{O}_{2}\right.$; Jamieson, 1998; Mascarenhas et al., 2008). In addition, HSP12 gene encodes a membrane protein whose function is to stabilize it under stress conditions, including oxidative stress. This protein has been shown to have a protective role when $S$. cerevisiae is exposed to sorbic acid (de Nobel et al., 2001). In the case of mutant strains lacking HSP12, an inhibition in their growth was observed (Welker et al., 2010).

The effect of light on microorganisms has generated great interest for further research, considering that it can result in the control of cellular functions, which could not be achieved with diffusion processes (Kusen et al., 2017). In addition, it would allow the activation of biological processes in a non-invasive way. Therefore, studies have been focusing on knowing how this exogenous factor may trigger the expression of genes involved in metabolic pathways of cellular importance (Binder et al., 2016). Thus, for example, it has been described that visible light is harmful to cells, affecting cellular respiration by destroying cytochromes (Epel and Butler, 1969; Ninnemann et al., 1970; Woodward et al., 1978; Ułaszewski et al., 1979) or by the production of ROS, which can react with biomolecules, such as lipids, nucleic acids, and proteins and inactivate their function (Toledano et al., 2003; Perrone et al., 2008). This causes oxidative stress in the cell, as does the presence of pCA (Piper, 1999).
Oxidative stress is caused by an imbalance between the cell antioxidant mechanism and ROS production (Toledano et al., 2003). ROS includes different oxidation states of dioxygen $\left(\mathrm{O}_{2}\right)$, such as singlet oxygen, superoxide anion $\left(\mathrm{O}_{2}^{-}\right), \mathrm{H}_{2} \mathrm{O}_{2}$, and hydroxyl radical $(\mathrm{OH} \bullet)$. These species are invariably produced in aerobic environments by different mechanisms, such as the "leakage" of electrons during biological oxidations, the action of flavin dehydrogenases, and the physical activation of oxygen molecules by radiation energy (Toledano et al., 2003; Bergamini et al., 2004).

It has been reported that visible light in $S$. cerevisiae alters its metabolism through changes in respiratory oscillation and the expression of the YAP1 gene, which codes for yeast activator protein-1 and is related to oxidative stress (Robertson et al., 2013). Under this stress, the cell has different responses depending on how severe the exposure to ROS is. At low doses, cells would adapt, becoming more resistant to a subsequent lethal dose (Jamieson, 1992). At higher doses, the cell activates antioxidant defense mechanisms at the transcriptional level, mainly through transcription factors, such as the Yaplp mentioned above, Msn2p, and Msn4p (Jamieson, 1998; Gasch et al., 2000; Moradas-Ferreira and Costa, 2000), also causing a delay in cell division (Lee et al., 1996; Chiu et al., 2011). Even higher doses can cause the death of a part of the population initially due to apoptosis and finally in extreme doses due to necrosis (Zong, 2006; Perrone et al., 2008; Farrugia and Balzan, 2012).

Considering the importance of $B$. bruxellensis at the industrial level, it is interesting to research how this yeast responds to two stresses present in its natural habitat: $p C A$ and light, allowing a deeper understanding of the metabolic ways of this spoilage yeast.

\section{MATERIALS AND METHODS}

\section{Microorganism}

B. bruxellensis LAMAP2480 strain was obtained from the collection at the Laboratory of Applied Microbiology and Biotechnology of the University of Santiago de Chile. The strain was grown in SD minimal medium $(2 \% \mathrm{w} / \mathrm{v}$ glucose and $6.7 \mathrm{~g} / \mathrm{l}$ yeast nitrogen base (YNB; Difco Laboratories, Detroit, United States) and kept in the dark until use).

\section{Growth Curves}

B. bruxellensis LAMAP2480 strain was grown in $5 \mathrm{ml}$ of SD minimum medium $(2 \% \mathrm{w} / \mathrm{v}$ glucose and $6.7 \mathrm{~g} / \mathrm{l}$ yeast nitrogen base (YNB; Difco Laboratories, Detroit, United States)) at $28^{\circ} \mathrm{C}$ until saturation (stationary phase). Then, $1 \times 10^{5}$ cells $/ \mathrm{ml}$ were inoculated in $200 \mu \mathrm{l}$ of the same medium in the absence and presence of $100 \mathrm{mg} / \mathrm{l}$ of $p \mathrm{CA}$ (Sigma-Aldrich, Inc.; United States) in triplicate on a Cell Culture Plate (SPL Life Sciences, Korea). The microplates were incubated at $28^{\circ} \mathrm{C}$ in the dark and at different light intensities using white fluorescent lamps at a light intensity of 2,500 lux and 4,000 lux. Varying light intensities were provided by adjusting the light with the help of Lux meter UNI-T UT 382 USB (Dongguan, China). Absorbance 
measurements were made at $600 \mathrm{~nm}$ for 10 days in the Epoch ${ }^{\mathrm{TM}}$ equipment (BioTek, United States), coupled to the Gen5 program (BioTek, United States).

The specific growth rate was determined by the slope of the exponential growth phase according to the equation $\mathrm{xt}=\mathrm{x} 0+\mu \mathrm{t}$, where $\mathrm{xt}$ and $\mathrm{x} 0$ represent the biomass in optical density (OD) at time $\mathrm{t}(\mathrm{h})$ and $t=0$, respectively (Barata et al., 2008). The lag phase was determined as described by Buchanan and Cygnarowicz (1990). All experiments were performed in triplicate.

\section{RNA Extraction}

B. bruxellensis LAMAP2480 strain was grown in SD minimal medium $(2 \% \mathrm{w} / \mathrm{v}$ glucose and $6.7 \mathrm{~g} / \mathrm{l}$ yeast nitrogen base (YNB; Difco Laboratories, Detroit, United States)) at $28^{\circ} \mathrm{C}$ until saturation. $1 \times 10^{5}$ cells $/ \mathrm{ml}$ were inoculated in $100 \mathrm{ml}$ of medium in the absence and presence of $100 \mathrm{mg} / \mathrm{l}$ of pCA (Sigma-Aldrich, Inc.; United States) at different light intensities (2,500 lux, 4,000 lux and in darkness). They were grown at $28^{\circ} \mathrm{C}$ until the end of lag phase (Godoy et al., 2016). Then, the culture was centrifuged at $1,370 \times g$ for $10 \mathrm{~min}$. The pellet was resuspended in $200 \mu \mathrm{l}$ of RNA Buffer $(50 \mathrm{~mm}$ Tris- $\mathrm{HCl} \mathrm{pH} 7.4 ; 100 \mathrm{~mm} \mathrm{NaCl} ; 10 \mathrm{~mm}$ EDTA), and $400 \mu \mathrm{l}$ of acidic phenol and glass beads were added. Vortex $1 \mathrm{~min}$, then ice $1 \mathrm{~min}$, and repeat $3 \mathrm{~min}$ in vortex. $200 \mu \mathrm{l}$ of RNA Buffer and $40 \mu \mathrm{l}$ of $10 \%$ SDS were added. It was stirred for $6 \mathrm{~min}$ at $65^{\circ} \mathrm{C}$. It was centrifuged at $16,000 \times g$ for $15 \mathrm{~min}$ at $4^{\circ} \mathrm{C}$, and the upper phase was collected. $400 \mu \mathrm{l}$ of acid phenol and $40 \mu \mathrm{l}$ of $3 \mathrm{M}$ sodium acetate were added, centrifuging at $16,000 \times g$ for $15 \mathrm{~min}$ at $4^{\circ} \mathrm{C}$ to finally collect the upper phase. Subsequently, $1 \mathrm{ml}$ of cold $96 \%$ ethanol was added, and it was refrigerated for $2 \mathrm{~h}$ at $-80^{\circ} \mathrm{C}$. It was centrifuged at $16,000 \times g$ for $10 \mathrm{~min}$ at $4^{\circ} \mathrm{C}$. Finally, the RNA Clean \& Concentrator ${ }^{\mathrm{TM}}$ -5 protocol (Zymo Research, United States) was followed. RNA quantification was performed in the Epoch ${ }^{\mathrm{TM}}$ equipment (BioTek, United States). All experiments were performed in triplicate.

\section{Quantification of Relative Expression}

The RQ1 RNase-Free DNase protocol (Promega, USA) was used for the RT-PCR. q-PCR was performed in qStepOnePlus Real-Time PCR System Thermal Cycling Block equipment (Thermo Fisher Scientific, United States) coupled to StepOne Software (v2.0; Applied Biosystems, United States). All the primers used were designed to amplify fragments between 100 and $300 \mathrm{bp}$ (Table 1). All reactions were performed in $20 \mathrm{uL}$ according to the $5 \mathrm{x}$ HOT FIREpol EvaGreen qPCR Mix Plus (ROX) protocol (Solis Biodyne, Estonia). The program used was as follows: $15 \mathrm{~min}$ at $95^{\circ} \mathrm{C}, 35$ amplification cycles at $95^{\circ} \mathrm{C}$ for $15 \mathrm{~s}, 60^{\circ} \mathrm{C}$ for $20 \mathrm{~s}$, and $72^{\circ} \mathrm{C}$ for $20 \mathrm{~s}$.

The relative quantification of the expression of the candidate genes of $B$. bruxellensis was carried out using the mathematical method $2-\Delta \Delta C T$ described by Livak and Schmittgen (2001), using actin 1 as the housekeeping gene. All experiments were performed in triplicate.

\section{Statistical Analysis}

The statistical analyses were carried out using ANOVA, and the mean values of the experiments were compared using the
TABLE 1 | List of primers used for RT-qPCR.

\begin{tabular}{llc}
\hline Primer $\left(\mathbf{5}^{\prime} \mathbf{-} \mathbf{3}^{\prime}\right)$ & Sequence & Tm $\left({ }^{\circ} \mathbf{C}\right)$ \\
\hline ACT1 F & GGT GAT GAC GCT CCA AGA & 64 \\
ACT1 R & TTG ACC CAT ACC GAC CAT AA & 63 \\
SOD1 F & GAG GGT AAC GAT CCA AA & 58 \\
SOD1 R & CAA AGA ACC AGC ATC AC & 58 \\
GCN4 F & CCA GGT GCT CT ATC TC & 58 \\
GCN4 R & CTC AGT ATT CCT AGC TCT C & 58 \\
HSP12 F & AAA CCA GCC ATC GAA AC & 60 \\
HSP12 R & CTC AAA GAG AGG AAG ACA AG & 59 \\
ESBP6 F & CAC GCA TAC CCT TTA TC & 57 \\
ESBP6 R & GAG GAA CAA GCA AGA AG & 57 \\
& &
\end{tabular}

LSD test. The treatments were considered significant when the values of $p \leq 0.05$. The analyses were done using Statgraphics Plus, version 5.1 (StatPoint Technologies, United States).

\section{RESULTS}

\section{Growth of $B$. bruxellensis in the Presence of Light and $p$-Coumaric Acid}

$B$. bruxellensis is the main contaminating yeast in the wine industry since it causes defects in the organoleptic properties of wine. Although $\mathrm{SO}_{2}$ is the compound that manages to control the growth of this yeast, it has been described that this compound can cause allergy problems in consumers, hence the interest in finding new control methods. B. bruxellensis can grow in various environmental stress conditions, including low nitrogen, low vitamin, high $\mathrm{SO}_{2}$ doses, low or high oxygen concentration, and high ethanol concentration. Considering this, innovative methods have been developed to reduce their contamination in wines, as are high hydrostatical pressure (HHP), pulse electric fields (PEF), ultrasound, UV light, and microwaves, among others (Pinto et al., 2020). These technologies are being studied to can be applied in the industry.

On the other hand, studies carried out in S. cerevisiae have shown that both the presence of hydroxycinnamic acids in the culture medium and light would affect its growth (Ułaszewski et al., 1979; Baranowski et al., 1980; Shu et al., 2009; Robertson et al., 2013). We evaluated how B. bruxellensis LAMAP2480 responds to these two factors ( $p$ CA and light). Growth curves were made in the absence and presence of $p \mathrm{CA}$, either in darkness or exposed to 2,500 and 4,000 lux, calculating their kinetic parameters (Figure 1A; Table 2). It is possible to observe that when the yeast was grown in darkness, the duration of the lag phase was $26.25 \mathrm{~h}$ in the absence and in the presence of $p C A$ (Table 2). This parameter, such as specific growth rate and generation time, did not show significant differences when comparing yeast behavior in the presence or absence of $p C A$.

In addition, when $B$. bruxellensis was exposed to a constant light intensity of 2,500 lux (Figure 1B; Table 2) in the presence of $p C A$, it was observed that the duration of the lag phase increased 3.75 times compared to control sample (darkness + $p C A)$ and its specific growth rate increased 1.75 times. The 


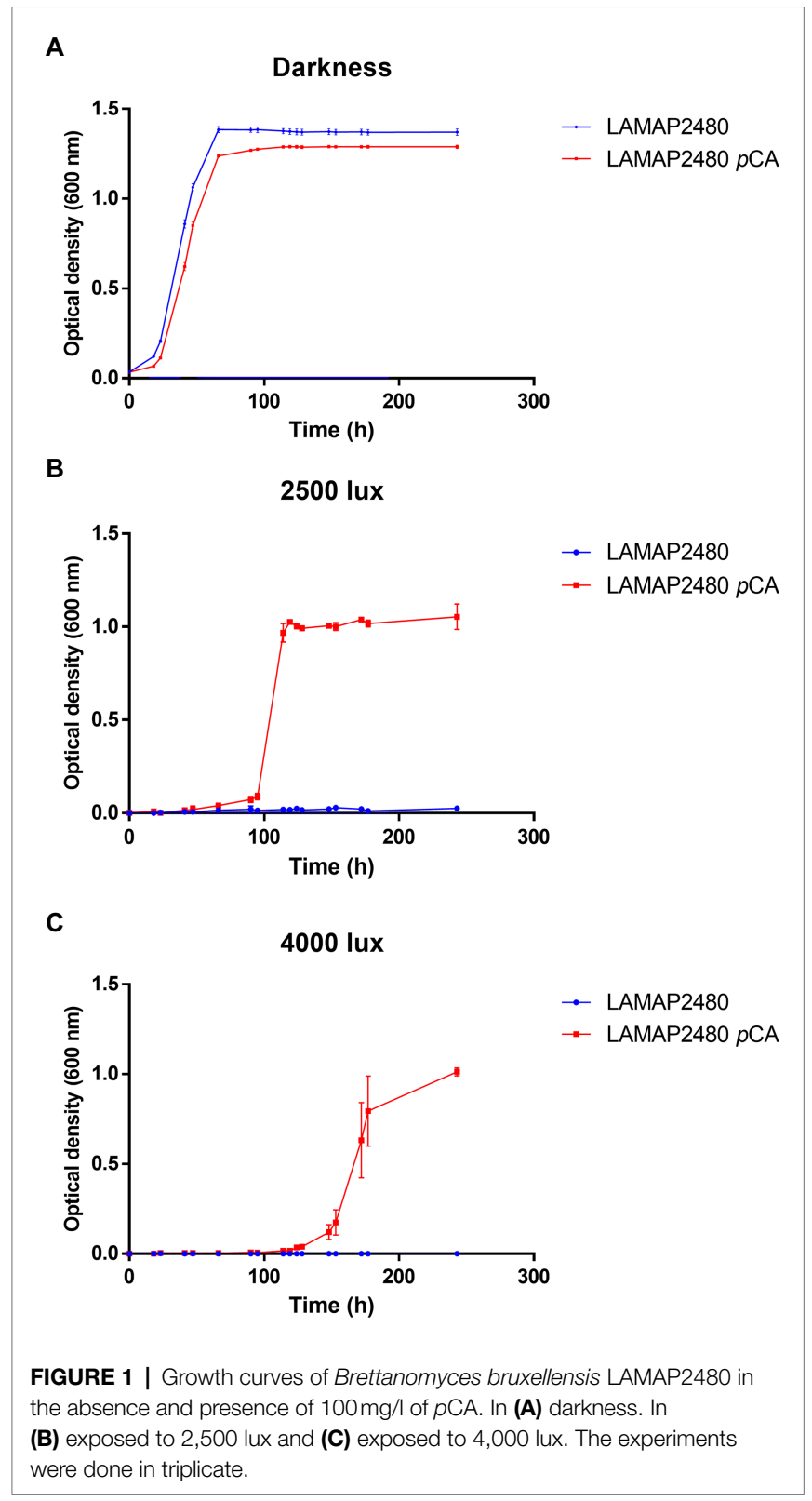

growth efficiency (calculated as area under the curve, considering $100 \%$ darkness + pCA) decreased by $55.8 \%$.

When the yeast was exposed to 4,000 lux (Figure 1C; Table 2), there was an increase in the duration of the lag phase of 6.19 times compared to the sample control (darkness $+p \mathrm{CA})$. The specific growth rate and generation time parameter did not show statistically significant differences with respect to the control. Additionally, the growth efficiency was $28.6 \%$, 3.5 times lower compared to the control.

Also, by comparing the growth of the cells to 2,500 lux and 4,000 lux, it was observed that the lag phase was lower to 2,500 lux (Figures 1B,C).

Furthermore, it was observed that yeast growth was negatively affected when it was exposed to both light intensities and in the absence of $p \mathrm{CA}$, where no growth was detected.
TABLE 2 | Kinetic parameters of growth B. bruxelllensis LAMAP2480 under different conditions.

\begin{tabular}{|c|c|c|c|}
\hline Condition & $\begin{array}{l}\text { Specific growth } \\
\text { rate } \mu \max \left(\mathrm{h}^{-1}\right)\end{array}$ & lag phase (h) & $\begin{array}{c}\text { Generation time } \\
{[\operatorname{Tg}(\mathrm{h})]}\end{array}$ \\
\hline Darkness & $0.0274 \pm 0.0004^{b}$ & $26.25 \pm 0.00^{\mathrm{a}}$ & $25.27 \pm 0.32^{b}$ \\
\hline Darkness $p C A$ & $0.0264 \pm 0.0001^{b}$ & $26.25 \pm 0.00^{\mathrm{a}}$ & $26.29 \pm 0.11^{b}$ \\
\hline $2,500 \mathrm{~lx}$ & $N G *$ & $N G *$ & $N G *$ \\
\hline $2,500 \mathrm{IxpCA}$ & $0.0462 \pm 0.0017^{a}$ & $98.5 \pm 0.00^{b}$ & $15.01 \pm 0.57^{\mathrm{a}}$ \\
\hline $4,0001 \mathrm{x}$ & NG* & $N G *$ & $N G *$ \\
\hline $4,000 \mathrm{lxp} p \mathrm{CA}$ & $0.0253 \pm 0.0058^{b}$ & $162.5 \pm 8.49^{\circ}$ & $28.14 \pm 6.45^{\mathrm{b}}$ \\
\hline
\end{tabular}

Mean $\pm S D(n=3)$. Different letters after means represent significant differences between conditions ( $p \leq 0.05)$. *NG: no growth. The experiments were done in triplicate.

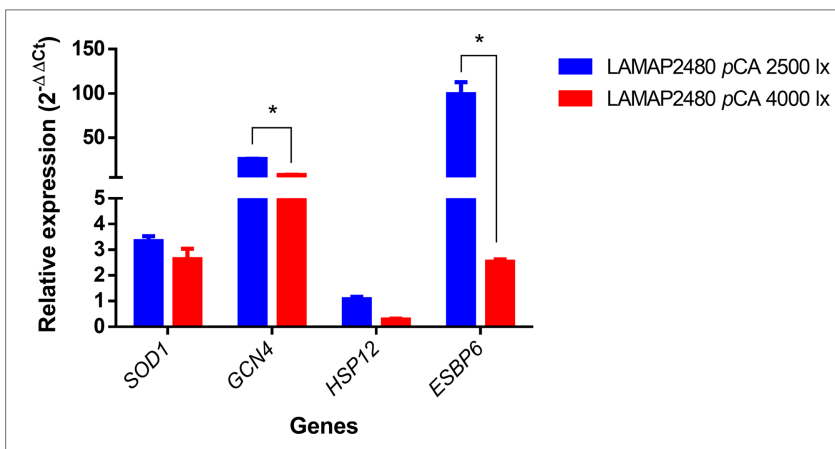

FIGURE 2 | Relative expression of genes related to oxidative stress during the lag phase of B. bruxellensis LAMAP2480 in the presence of pCA. Data were statistically analyzed using least significant difference (LSD) statistical test with a $95 \%$ confidence level. Asterisks represent significance $\left({ }^{*} p<0.05\right)$.

\section{Relative Gene Expression}

Light would induce gene expression related to oxidative stress (Toledano et al., 2003; Perrone et al., 2008). To evaluate the response of genes associated with this type of stress in $B$. bruxellensis LAMAP2480, different light intensities were tested. The relative expression at the end of the lag phase of some genes previously associated with oxidative stress in $S$. cerevisiae was quantified in B. bruxellensis in this study (Figure 2).

These results indicated that SOD1, GCN4, and ESBP6 genes were overexpressed $(E R \geqslant 2)$ at 2,500 and 4,000 lux. Particularly, the GCN4 and ESBP6 genes expression was 3.3 and 39.6 times higher respectively, compared to the 4,000 lux condition, being statistically significant.

For the HSP12 gene, no overexpression was observed in any condition.

\section{DISCUSSION}

The study of the growth control of B. bruxellensis is very important in winemaking, considering the need to reduce the use of $\mathrm{SO}_{2}$. This yeast has shown great resistance to different stress conditions during its growth in wine, being able to form spores (Dekkera species teleomorph) to survive. B. bruxellensis is resistant to different enological factors as high ethanol concentration, low $\mathrm{pH}$, low oxygen transfer rate, and residual 
ammonium scarcity (Curtin et al., 2015; Pinto et al., 2020). Hence, it the importance of looking for new control methods to avoid contamination in winemaking.

Folch-Mallol et al. (2004) reported a mechanism called cross-protection in S. cerevisiae. This consists of adapting the microorganisms to a specific type of stress, which would allow it to resist other stress factors, although these are lethal in the absence of a previous induction. The molecular base would be to activate different stress genes involved in adaptive responses (Brown et al., 2014; Święciło, 2016). In this sense, the light stress to which B. bruxellensis LAMAP2480 was exposed in the absence of $p C A$ affected yeast growth; however, the presence of another stressor, such as $p C A$, allowed $B$. bruxellensis LAMAP2480 to adapt to light stress, observing an increase in the expression of genes related to stress to oxidative, suggesting a possible stress-protective effect by $p \mathrm{CA}$ at cellular level.

Various environmental stress conditions, including high light intensities, extreme temperatures, and metals, among others, can induce oxidative stress and accelerated formation of ROS. In general, it has been described that visible light would produce ROS by endogenous photosensitizers, such as flavins and porphyrins (Molin et al., 2020). In this respect, hydroxycinnamic acids, such as $p C A$, and flavonoids, normally present in plants and fruits, exhibit radical scavenging ability (Scandalios, 2005; Yingbin et al., 2019).

In agreement with our results, Bayliak et al. (2016) evaluated the effect of quercetin, one flavonoid, on stress resistance of exponentially growing $S$. cerevisiae cell exposure to hydrogen peroxide, copper ions, and heat shock. Quercetin increased stress resistance in the yeast $S$. cerevisiae via antioxidants related at high concentrations providing partial protection to proteins against ROS-induced modification under heat shock and oxidative stress exposure.

There are no studies of the effect of light on the growth of B. bruxellensis, but few have been carried out on S. cerevisiae (Woodward et al., 1978; Ułaszewski et al., 1979; Edmunds, 1980; Robertson et al., 2013). The same occurs with studies at the genetic level on changes in gene expression in these yeasts when exposed to visible light.

Woodward et al. (1978) observed that at 1250 lux, the growth of $S$. cerevisiae is not affected; however, when increasing the intensity of the light (over 1,250 lux), the generation time of the yeast increases progressively. Studies carried out in S. cerevisiae indicate that this is due to the inhibition of the transport of sugars and amino acids. Furthermore, it was described that increasing growth temperature and light intensity also has a negative effect on yeast growth. Robertson et al. (2013) observed that $S$. cerevisiae expresses yeast activator protein-1 gene (YAP1) related to ROS response when exposed to visible light. This gene regulates several genes with antioxidant functions, such as thioredoxin reductase (TTR1), cytosolic thioredoxin (TRX2), and cytochrome-c peroxidase (CCP1). Yap1p would play an important role in the yeast's ability to tolerate the harmful effects of visible light. These same authors showed that in those cells with a deficiency in the ROS response, light would have a negative effect on their growth.
Like YAP1, GCN4 is part of the b-ZIP family of transcriptional factors (Rodrigues-Pousada et al., 2010) and has been shown to protect the cell under conditions of oxidative stress (Jamieson, 1998; Folch-Mallol et al., 2004; Mascarenhas et al., 2008). In S. cerevisiae, it has been reported that mutants lacking the GCN4 gene do not grow when exposed to different concentrations of $\mathrm{H}_{2} \mathrm{O}_{2}$. Our results show overexpression of GCN4 gene in both light intensities, which could be related to the antioxidant response induced by the presence of $p C A$ in the medium.

SOD1 encodes a cytosolic copper-zinc superoxide dismutase which catalyzes the dismutation of the superoxide radical $\left(\mathrm{O}_{2}^{-}\right)$ to oxygen $\left(\mathrm{O}_{2}\right)$ and $\mathrm{H}_{2} \mathrm{O}_{2}$ (Steinman, 1980). de Nobel et al. (2001) reported a comparative analysis between the proteome and transcriptome of $S$. cerevisiae when exposed to sorbic acid, which is a weak acid as $p C A$ is. The results indicated that SOD1 is overexpressed in response to sorbic acid in S. cerevisiae, suggesting that it is part of the resistance mechanism to this acid. Some microorganisms can adapt quickly to a second stress type, having been previously exposed to another stress. For example, in Candida albicans, oxidative stress induces heat shock genes regulation, and S. cerevisiae has protection against oxidative stress if cells have been exposed to a mild heat shock. This protection stress would have unexpected responses to classical regulatory pathways to a specific stress due to combinatorial cross-talk (Brown et al., 2014).

Molin et al. (2020) have concluded that the protein kinase A plays a key role in yeast growth in the presence of light, which would be a circadian mechanism that is somehow conserved in yeast and mammals. These authors demonstrated that the presence of light reduces protein kinase A activity, which would be vital for cells when grown in the presence of light since mutants that were sensitive to light had a protein kinase A activity well above those of normal levels.

Sugiyama et al. (2016) reported the overexpression of ESBP6 gene in the presence of lactic acid. Through gene disruption and overexpression experiments, ESBP6 gene was shown to be involved in response to lactic acid adaptation in S. cerevisiae, although it does not appear to be involved in the transport of monocarboxylic acids. The overexpression of this gene suggests that it plays a fundamental role in the adaptation of $S$. cerevisiae to lactic acid. ESBP6 interacts with various proteins in response to stress (Hsp70, Hsp82, Hsp90, Ssa1, and Ssa2). These chaperones allow the refolding of denatured proteins, stabilize the interaction of proteins or transport, and degrade damaged proteins, which is crucial in adapting to weak acids since this causes an increase in intracellular $\mathrm{pH}$, affecting the structure and function of the yeast proteins. In addition, Pereira et al. (2020) demonstrated that overexpression of ESBP6 gene generated greater resistance to aromatic acids, including $p \mathrm{CA}$, reducing the stress level in the cell by promoting biomass yield. Our results suggest that pCA-induced overexpression of ESBP6 has a protective effect against light stress, allowing cell growth.

Cross-stress can show a low specify in defense/reparation mechanism, allowing alternatives mechanism with a similar biochemical response to assure important functions of a cell as a response to different types of stress can be translated 
into a stress adaptation highly relevant to the natural environment (Święciło, 2016).

It has been described that the incidence of light on yeast growth would depend on the initial concentration of the culture. It is possible that by increasing the cell biomass, there is protection of the external cells over the internal cells of the culture. The outer cells would absorb light energy, preventing the inner cells from being affected by the toxic effects of light, allowing their normal division (Molin et al., 2020). Also, we think the phase of growth is important. In the case of saturation phase, some of the principal structures to inhibit the effects of light should be actives, as are the cytochromes (Ułaszewski et al., 1979), or in this stage, the cellular wall should be totally formed, transformed into a barrier for the entry of light to the interior of the cell. Our experiments were carried out with the same initial concentration of cells, but it is an interesting point to consider for future trials.

Different environmental factors can activate the response to oxidative stress in microorganisms. Among them, we have the presence of hydroxycinnamic acids (a natural compound) and sunlight. In addition, it has been described that if a microorganism is exposed to more than one stress factor, it will acquire an overprotective quality. That is, the cell could trigger more than one defense response in such a way as to allow it to adapt to grow in the presence of various stressors. To our knowledge, our study is the first report on the effect of light on B. bruxellensis growth.

Our results showed that, in the case of B. bruxellensis, when exposed to a concentration of $100 \mathrm{mg} / \mathrm{l}$ of $p \mathrm{CA}$ and in the absence of light, the duration of the lag phase slightly increased, since after adapting to the culture medium, its growth reached similar optical density values as the control sample (absence of $p C A)$. It was also observed that when yeast was exposed to $p \mathrm{CA}$ and light $(2,500$ and 4,000 lux $)$, the duration of the lag phase was statistically longer compared to when the yeast

\section{REFERENCES}

Baranowski, J. D., Davidson, P. M., Nagel, C. W., and Branen, A. L. (1980). Inhibition of Saccharomyces cerevisiae By naturally occurring hydroxycinnamates. J. Food Sci. 45, 592-594. doi: 10.1111/j.1365-2621.1980. tb04107.x

Barata, A., Caldeira, J., Botelheiro, R., Pagliara, D., Malfeito-Ferreira, M., and Loureiro, V. (2008). Survival patterns of Dekkera bruxellensis in wines and inhibitory effect of Sulphur dioxide. Int. J. Food Microbiol. 121, 201-207. doi: 10.1016/j.ijfoodmicro.2007.11.020

Bayliak, M. M., Burdylyuk, N. I., and Lushchak, V. I. (2016). Quercetin increases stress resistance in the yeast Saccharomyces cerevisiae not only as an antioxidant. Ann. Microbiol. 66, 569-576. doi: 10.1007/s13213-015-1136-8

Bergamini, C., Gambetti, S., Dondi, A., and Cervellati, C. (2004). Oxygen, reactive oxygen species and tissue damage. Curr. Pharm. Des. 10, 1611-1626. doi: $10.2174 / 1381612043384664$

Binder, D., Frohwitter, J., Mahr, R., Bier, C., Grünberger, A., Loeschcke, A., et al. (2016). Light-controlled cell factories: employing Photocaged isopropyl$\beta$-d-Thiogalactopyranoside for light-mediated optimization of lac promoterbased gene expression and (+)-Valencene biosynthesis in Corynebacterium glutamicum. Appl. Environ. Microbiol. 82, 6141-6149. doi: 10.1128/ AEM.01457-16 is grown with $p \mathrm{CA}$ in the absence of light. This suggests that the response of $B$. bruxellensis LAMAP2480 would be related to cross-protection when exposed to both stressors. However, other effects of $p C A$ and light on the cells should not be discarded.

Furthermore, expression levels of the genes indicated overexpression of the SOD1, GCN4, and ESBP6 genes for both light intensities in the presence of $p C A$, suggesting that the presence of $p C A$ stimulates an antioxidant response allowing the growth of $B$. bruxellensis exposed at 2,500 and 4,000 lux. Although the effect of light causes an increase in the duration of lag phase, $B$. bruxellensis LAMAP2480 can adapt and, despite having a decrease in growth efficiency, can grow to a high concentration of cells.

\section{DATA AVAILABILITY STATEMENT}

The original contributions presented in the study are included in the article/supplementary material, further inquiries can be directed to the corresponding authors.

\section{AUTHOR CONTRIBUTIONS}

LG, DC, and MG: conceptualization and writing - preparation of original draft, review, and editing. LG and DC: formal analysis and methodology. MG: funding acquisition. MS: supervision. All authors have read and agreed to the published version of the manuscript.

\section{FUNDING}

This research was funded by ANID/CONICYT FONDECYT Iniciación 11180979 and Postdoct DICYT 081871GM POSTDOC Universidad de Santiago de Chile. Millennium Nucleus for Fungal Integrative and Synthetic Biology (NC120043) and Dicyt-USACH.

Brown, A. J. P., Budge, S., Kaloriti, D., Tillmann, A., Jacobsen, M. D., Yin, Z., et al. (2014). Stress adaptation in a pathogenic fungus. J. Exp. Biol. 217, 144-155. doi: 10.1242/jeb.088930

Buchanan, R. L., and Cygnarowicz, M. L. (1990). A mathematical approach toward defining and calculating the duration of the lag phase. Food Microbiol. 7, 237-240. doi: 10.1016/0740-0020(90)90029-H

Chatonnet, P., Dubourdieu, D., and Boidron, J. N. (1995). The influence of Brettanomyces/Dekkera sp. yeasts and lactic acid bacteria on the ethylphenol content of red wines. Am. J. Enol. Vitic. 46, 463-468.

Chiu, J., Tactacan, C. M., Tan, S.-X., Lin, R. C. Y., Wouters, M. A., and Dawes, I. W. (2011). Cell cycle sensing of oxidative stress in Saccharomyces cerevisiae by oxidation of a specific cysteine residue in the transcription factor Swi6p. J. Biol. Chem. 286, 5204-5214. doi: 10.1074/jbc.M110.172973

Curtin, C., Varela, C., and Borneman, A. (2015). Harnessing improved understanding of Brettanomyces bruxellen sisbiology to mitigate the risk of wine spoilage. Aust. J. Grape Wine Res. 21, 680-692. doi: 10.1111/ajgw.12200

de Nobel, H., Lawrie, L., Brul, S., Klis, F., Davis, M., Alloush, H., et al. (2001). Parallel and comparative analysis of the proteome and transcriptome of sorbic acid-stressed Saccharomyces cerevisiae. Yeast 18, 1413-1428. doi: 10.1002/ yea.793

Edmunds, L. N. (1980). "Blue-light photoreception in the inhibition and synchronization of growth and transport in the yeast saccharomyces," in The Blue Light Syndrome, vol. 584-596 (Berlin, Heidelberg: Springer) doi: 10.1007/978-3-642-67648-2_53 
Epel, B., and Butler, W. L. (1969). Cytochrome a3: destruction by light. Science 166, 621-622. doi: 10.1126/science.166.3905.621

Farrugia, G., and Balzan, R. (2012). Oxidative stress and programmed cell death in yeast. Front. Oncol. 2:64. doi: 10.3389/fonc.2012.00064

Fleet, G. H. (2003). Yeast interactions and wine flavour. Int. J. Food Microbiol. 86, 11-22. doi: 10.1016/s0168-1605(03)00245-9

Folch-Mallol, J. L., Garay-Arroyo, A., Lledías, F., and Covarrubias Robles, A. A. (2004). The stress response in the yeast Saccharomyces cerevisiae. Rev. Latinoam. Microbiol. 46, 24-46.

Gasch, A. P., Spellman, P. T., Kao, C. M., Carmel-Harel, O., Eisen, M. B., Storz, G., et al. (2000). Genomic expression programs in the response of yeast cells to environmental changes. Mol. Biol. Cell 11, 4241-4257. doi: $10.1091 / \mathrm{mbc} .11 .12 .4241$

Godoy, L., Vera-Wolf, P., Martinez, C., Ugalde, J. A., and Ganga, M. A. (2016). Comparative transcriptome assembly and genome-guided profiling for Brettanomyces bruxellensis LAMAP2480 during p-coumaric acid stress. Sci. Rep. 6:34304. doi: 10.1038/srep34304

Jamieson, D. J. (1992). Saccharomyces cerevisiae has distinct adaptive responses to both hydrogen peroxide and menadione. J. Bacteriol. 174, 6678-6681. doi: $10.1128 / \mathrm{jb} .174 .20 .6678-6681.1992$

Jamieson, D. J. (1998). Oxidative stress responses of the yeast Saccharomyces cerevisiae. Yeast 14, 1511-1527. doi: 10.1002/(sici)1097-0061(199812)14:16 $<1511$ ::aid-yea356>3.0.co;2-s

Kusen, P. M., Wandrey, G., Krewald, V., Holz, M., Berstenhorst, S. M. Z., Büchs, J., et al. (2017). Light-controlled gene expression in yeast using photocaged $\mathrm{Cu}^{2+}$. J. Biotechnol. 258, 117-125. doi: 10.1016/j.jbiotec.2017.04.032

Lee, J., Romeo, A., and Kosman, D. J. (1996). Transcriptional remodeling and G1 arrest in dioxygen stress in Saccharomyces cerevisiae. J. Biol. Chem. 271, 24885-24893. doi: 10.1074/jbc.271.40.24885

Livak, K. J., and Schmittgen, T. D. (2001). Analysis of relative gene expression data using real- time quantitative PCR and the 2- $\Delta \Delta$ CT Method. 25, 402-408. doi: 10.1006/meth.2001.1262

Loureiro, V. (2003). Spoilage yeasts in the wine industry. Int. J. Food Microbiol. 86, 23-50. doi: 10.1016/S0168-1605(03)00246-0

Mascarenhas, C., Edwards-Ingram, L. C., Zeef, L., Shenton, D., Ashe, M. P., and Grant, C. M. (2008). Gcn4 is required for the response to peroxide stress in the yeast Saccharomyces cerevisiae. Mol. Biol. Cell 19, 2995-3007. doi: $10.1091 / \mathrm{mbc} . \mathrm{e} 07-11-1173$

Molin, M., Logg, K., Bodvard, K., Peeters, K., Forsmark, A., Roger, F., et al. (2020). Protein kinase A controls yeast growth in visible light. BMC Biol. 18:168. doi: $10.1186 / \mathrm{s} 12915-020-00867-4$

Moradas-Ferreira, P., and Costa, V. (2000). Adaptive response of the yeast Saccharomyces cerevisiae to reactive oxygen species: defences, damage and death. Redox Rep. 5, 277-285. doi: 10.1179/135100000101535816

Ninnemann, H., Butler, W. L., and Epel, B. L. (1970). Inhibition of respiration in yeast by light. Biochim. Biophys. Acta Bioenerg. 205, 499-506. doi: 10.1016/0005-2728(70)90115-5

Oelofse, A., Pretorius, I. S., and Du Toit, M. (2008). Significance of Brettanomyces and Dekkera during winemaking: A synoptic review. S. Afr. J. Enol. Vitic. 29, 128-144. doi: 10.21548/29-2-1445

Pereira, R., Mohamed, E. T., Radi, M. S., Herrgård, M. J., Feist, A. M., Nielsen, J., et al. (2020). Elucidating aromatic acid tolerance at low pH in Saccharomyces cerevisiae using adaptive laboratory evolution. Proc. Natl. Acad. Sci. 117, 27954-27961. doi: 10.1073/pnas.2013044117

Perrone, G. G., Tan, S.-X., and Dawes, I. W. (2008). Reactive oxygen species and yeast apoptosis. Biochim. Biophys. Acta. 1783, 1354-1368. doi: 10.1016/j. bbamcr.2008.01.023

Pinto, L., Baruzzi, F., Cocolin, L., and Malfeito-Ferreira, M. (2020). Emerging technologies to control Brettanomyces spp. In wine: recent advances and future trends. Trends Food Sc. Technol. 99, 88-100. doi: 10.1016/j.tifs.2020.02.013

Piper, P. W. (1999). Yeast superoxide dismutase mutants reveal a pro-oxidant action of weak organic acid food preservatives. Free Radic. Biol. Med. 27, 1219-1227. doi: 10.1016/s0891-5849(99)00147-1

Robertson, J. B., Davis, C. R., and Johnson, C. H. (2013). Visible light alters yeast metabolic rhythms by inhibiting respiration. Proc. Natl. Acad. Sci. U. S. A. 110, 21130-21135. doi: 10.1073/pnas.1313369110
Rodrigues-Pousada, C., Menezes, R. A., and Pimentel, C. (2010). The Yap family and its role in stress response. Yeast 27, 245-258. doi: 10.1002/yea.1752

Scandalios, J. G. (2005). Oxidative stress: molecular perception and transduction of signals triggering antioxidant gene defenses. Braz. J. Med. Biol. Res. 38, 995-1014. doi: $10.1590 /$ s0100-879x2005000700003

Shu, C.-H., Huang, C.-K., and Tsai, C.-C. (2009). Effects of light wavelength and intensity on the production of ethanol by Saccharomyces cerevisiae in batch cultures. J. Chem. Technol. Biotechnol. 84, 1156-1162. doi: 10.1002/ jctb. 2148

Steinman, H. M. (1980). The amino acid sequence of copper-zinc superoxide dismutase from bakers' yeast. J. Biol. Chem. 255, 6758-6765. doi: 10.1016/ s0021-9258(18)43637-x

Suárez, R., Suárez-Lepe, J. A., Morata, A., and Calderón, F. (2007). The production of ethylphenols in wine by yeasts of the genera Brettanomyces and Dekkera: A review. Food Chem. 102, 10-21. doi: 10.1016/j. foodchem.2006.03.030

Sugiyama, M., Akase, S.-P., Nakanishi, R., Kaneko, Y., and Harashima, S. (2016). Overexpression of ESBP6 improves lactic acid resistance and production in Saccharomyces cerevisiae. J. Biosci. Bioeng. 122, 415-420. doi: 10.1016/j. jbiosc.2016.03.010

Święciło, A. (2016). Cross-stress resistance in Saccharomyces cerevisiae yeastnew insight into an old phenomenon. Cell Stress Chaperones. 21, 187-200. doi: 10.1007/s12192-016-0667-7

Toledano, M. B., Delaunay, A., Biteau, B., Spector, D., and Azevedo, D. (2003). Oxidative stress responses in yeast. Top. Curr. Genet. 1, 1511-1527. doi: 10.1007/3-540-45611-2_6

Ułaszewski, S., Mamouneas, T., Shen, W. K., Rosenthal, P. J., Woodward, J. R., Cirillo, V. P., et al. (1979). Light effects in yeast: evidence for participation of cytochromes in photoinhibition of growth and transport in Saccharomyces cerevisiae cultured at low temperatures. J. Bacteriol. 138, 523-529. doi: 10.1128/jb.138.2.523-529.1979

Wedral, D., Shewfelt, R., and Frank, J. (2010). The challenge of Brettanomyces in wine. LWT Food Sci. Technol. 43, 1474-1479. doi: 10.1016/j. lwt.2010.06.010

Welker, S., Rudolph, B., Frenzel, E., Hagn, F., Liebisch, G., Schmitz, G., et al. (2010). Hsp12 is an intrinsically unstructured stress protein that folds upon membrane association and modulates membrane function. Mol. Cell 39, 507-520. doi: 10.1016/j.molcel.2010.08.001

Woodward, J. R., Cirillo, V. P., and Edmunds, L. N. Jr. (1978). Light effects in yeast: inhibition by visible light of growth and transport in Saccharomyces cerevisiae grown at low temperatures. J. Bacteriol. 133, 692-698. doi: 10.1128/ jb.133.2.692-698.1978

Yingbin, S., Xun, S., Li, L., Jian, S., Yogini, J., Junqing, H., et al. (2019). Protective effects of p-coumaric acid against oxidant and hyperlipidemia-an in vitro and in vivo evaluation. Biomed. Pharmacother. 111, 579-587. doi: 10.1016/j.biopha.2018.12.074

Zong, W.-X. (2006). Necrotic death as a cell fate. Genes Dev. 20, 1-15. doi: $10.1101 /$ gad.1376506

Conflict of Interest: The authors declare that the research was conducted in the absence of any commercial or financial relationships that could be construed as a potential conflict of interest.

Publisher's Note: All claims expressed in this article are solely those of the authors and do not necessarily represent those of their affiliated organizations, or those of the publisher, the editors and the reviewers. Any product that may be evaluated in this article, or claim that may be made by its manufacturer, is not guaranteed or endorsed by the publisher.

Copyright $\odot 2021$ Catrileo, Moreira, Ganga and Godoy. This is an open-access article distributed under the terms of the Creative Commons Attribution License (CC BY). The use, distribution or reproduction in other forums is permitted, provided the original author(s) and the copyright owner(s) are credited and that the original publication in this journal is cited, in accordance with accepted academic practice. No use, distribution or reproduction is permitted which does not comply with these terms. 